\title{
A review of family influences on travel decision making
}

\begin{abstract}
Worldwide, there are an increasing number of tourists travelling abroad together as a family, with family members ranging from 3 to 7 persons, and 3 to 50 years of age. These groups of family tourists have illustrated some unique needs which entail further investigation if industry players were to meet and satisfy their needs more effectively. This paper reviews the existing literature on family decision making, paying attention to specific requirements of family needs while travelling. Specific needs of this type of tourists include children-friendly menus, kids clubs, family travel packages, family-friendly environment, and wellness facilities for family members of different age groups etc. The paper reviews existing tourism typologies and concluded that there is a need to develop a new typology for family tourists. This paper proposes three new dimensions for tourist typologies, i.e. cultural-influence (religion), customer characteristic (stage in family life cycle) and destination services (family-friendly facilities).
\end{abstract}

Keyword: Family decision making; Family life cycles; Tourist typology; Travel decision 